\title{
EDUCAÇÃO AMBIENTAL EMANCIPATÓRIA NA ESCOLA: POSSIBILIDADES DA PRÁTICA EDUCATIVA DOCENTE
}

\author{
Izabela Carvalho BENTO' e Áurea Regina Guimarães THOMAZI ${ }^{2}$ \\ Centro Universitário UNA - Campus Belo Horizonte \\ belascarvalho@gmail.com'- aureagt@gmail.com²
}

Artigo submetido em novembro/2013 e aceito em dezembro/2013

\section{RESUMO}

A educação ambiental é um tema transversal que deve estar presente em todas as disciplinas do ensino fundamental e médio, devido ao posicionamento em que a nossa natureza se encontra, principalmente nos dias atuais, início do século XXI. Este tema tornou-se importante por dar suporte ao professor para que ele possa trabalhar com os alunos o tema relacionado ao meio ambiente de forma mais participativa, crítica e consciente, com a intenção de desacelerar a destruição dos nossos recursos naturais e proteger mais a natureza, incluindo o próprio ser humano e sua qualidade de vida. Este artigo apresenta o trabalho desenvolvido nas escolas de ensino fundamental e médio do município de Aimorés (MG), promovido pelo Instituto Terra, como um caso bem-sucedido em educação ambiental, mostrando que é possível modificar uma realidade natural local com educação ambiental no contexto escolar, em uma perspectiva emancipatória na qual o aluno é mais dinâmico, crítico e participativo em suas atitudes em relação ao meio ambiente.

PALAVRAS-CHAVE: Educação Ambiental emancipatória, Práticas pedagógicas, Desenvolvimento Local.

\section{EMANCIPATORY ENVIRONMENTAL EDUCATION IN SCHOOLS: POSSIBILITIES OF EDUCATIONAL PRACTICES BY TEACHERS}

\begin{abstract}
This research intended to know how is made the process of environmental education in a school's context, supported by "Instituto Terra", located in the city of Aimorés, state of Minas Gerais, analyzing the possibilities of this pedagogical practice. Environmental education is a transversal theme that must be present in all subjects of High School and Elementary School, due to the situation that our environment is, mainly in the present days, beginning of XXI century. This subject became important because it provides the teachers support to work with the students about how to deal with environmental issues in a more participative,
\end{abstract}

critical and conscious way, with the intention to slow down the destruction of our natural resources and protect more the nature, including the human being itself, and its quality of life. As a result of a research, this study propose to present the work developed by "Instituto Terra" with state schools in the city of Aimorés, as a successful case regarding environmental education, demonstrating that is possible to change a local natural reality with strong and present environmental teaching in school's context, in which the student is more dynamic, critic and participative in his behavior towards the environment.

KEYWORDS: Emancipatory environmental education, Pedagogical practices, Local development. 


\section{EDUCAÇÃO AMBIENTAL EMANCIPATÓRIA NA ESCOLA: POSSIBILIDADES DA PRÁTICA EDUCATIVA DOCENTE}

\section{INTRODUÇÃO}

As discussões sobre a educação ambiental (EA) e uma sociedade sustentável ampliaramse progressivamente a partir de 1980. Ao discutir sobre meio ambiente, educação ambiental e uma sociedade sustentável, percebe-se que o significativo aumento da população mundial teve, entre suas consequências, a degradação dos recursos naturais de maneira exacerbada, muitas vezes em decorrência da má-exploração e do consumo excessivo desses recursos, cada vez mais reforçado pelo modo de produção capitalista.

Com a degradação acelerada dos recursos naturais, tornou-se necessária a busca de novos meios e de novas políticas para proporcionar a conservação desses recursos e o controle do crescimento da população, além de investir numa mudança radical ligada ao consumo e à procriação. Pensando na preservação ambiental e numa sociedade sustentável, a Organização das Nações Unidas (ONU) realizou, em 1972, em Estocolmo, Suécia, a Primeira Conferência Mundial de Meio Ambiente Humano, no intuito de colocar o problema ambiental em nível planetário. $O$ grande tema discutido nessa conferência foi a poluição ocasionada principalmente pelas indústrias. A educação ambiental surge a partir de uma resolução importante dessa conferência, a qual relata que se deve educar o cidadão para a solução dos problemas ambientais.

De acordo com a Lei 9.795, a educação ambiental é considerada um tema transversal, portanto, deve estar em presente em todas as disciplinas do contexto escolar e em todos os níveis de ensino, visto que "o ambiente escolar é um dos locais privilegiados para a realização da educação ambiental, desde que dê oportunidade à criatividade, ao debate, à pesquisa e à participação de todos" [1].

A educação ambiental emancipatória é considerada ideal para ser aplicada e praticada nas escolas, pois além de instigar o aluno a participar e envolver-se em determinado tema ligado ao meio ambiente, ela proporciona mudanças de comportamentos e estimula a cidadania por intermédio da participação social. Assim, favorece transformações de uma realidade em relação aos problemas ambientais, além de envolver todos os alunos, professores e comunidade escolar.

Diante disso, a EA assume cada vez mais uma função transformadora na qual a corresponsabilização dos indivíduos torna-se um objetivo essencial para a promoção de um desenvolvimento sustentável. Nesse sentido, o educador tem a função de mediador na construção de referenciais ambientais e deve saber usá-los como instrumentos para o desenvolvimento de uma prática social centrada no conceito da natureza. Com essa responsabilidade atribuída aos educadores, é possível dizer que as práticas educativas são consideradas ferramentas essenciais para o trabalho dos docentes, para o trabalho de EA, pois conduzem o aluno aos temas relacionados ao meio ambiente, possibilitando, assim, mudanças de posturas, de comportamentos e reflexões.

Ao relacionar os temas: educação ambiental emancipatória, mudanças de posturas em relação aos recursos naturais, práticas educativas e sucesso no trabalho docente no que diz respeito ao tema EA no ambiente escolar, este trabalho voltou-se para as práticas docentes desenvolvidas em escolas com o apoio do Instituto Terra, fundado em 1998 por Lélia Deluiz 
Wanick Salgado e Sebastião Salgado, situado no município de Aimorés (MG). Trata-se de uma reserva particular do patrimônio natural, constituída em uma área degradada de mata atlântica, a qual realiza projetos de educação ambiental. Tem como objetivos: promover, executar e apoiar programas e ações concretas de conservação, recuperação, gestão e educação ambiental na mata atlântica da bacia do Rio Doce, a partir de quatro componentes: recuperação ambiental, pesquisa, educação e desenvolvimento sustentável [2].

\section{METODOLOGIA UTILIZADA}

A pesquisa foi baseada em dados qualitativos, envolvendo a experiência de seis professores de áreas diversas do ensino médio e fundamental, das escolas da rede privada e pública de Aimorés, e dois gestores ambientais. Foi feita investigação bibliográfica como preparação à pesquisa de campo, com o objetivo de oferecer dados e conceitos sobre a educação ambiental e práticas educativas.

O instrumento utilizado foi a entrevista, com o intuito de identificar as práticas educativas utilizadas pelos professores, mas também detectar a existência de dificuldades e possibilidades e quais são elas.

A entrevista empregada foi do tipo semiestruturada, em que as questões foram elaboradas e definidas seguindo um roteiro de cinco perguntas que convidavam o entrevistado a expor suas opiniões e experiências em relação ao tema educação ambiental no contexto escolar. A finalidade foi conhecer, entender, captar e analisar o que os professores entendiam sobre a EA e de que forma eles a abordavam, aplicavam e trabalhavam no âmbito escolar. A análise dos dados obtidos baseou-se em Bardin (2011) [3].

\section{RESULTADOS E DISCUSSÃO}

\subsection{O conceito de educação ambiental no contexto escolar na visão dos docentes}

Ao ser perguntado para os participantes desta pesquisa qual o conceito de educação ambiental, obtiveram-se três definições diferentes, conforme apresentado na Tabela a seguir.

Tabela 1 - Conceito de EA no ponto de vista dos oito entrevistados

\begin{tabular}{l|c}
\hline \multicolumn{1}{c|}{ Categorias } & Ocorrência \\
\hline Preservação do meio ambiente, respeito à natureza & E1, E2, E6, E7, E8 \\
\hline Relação aluno x escola x família natureza & E3, E4, \\
\hline É um tema transversal que deve estar presente em todas as disciplinas & E5 \\
\hline
\end{tabular}

Fonte: dados das entrevistas.

De acordo com os entrevistados, que serão identificados como E1 a E8, para preservar suas identidades, verificou-se predomínio da preservação do meio ambiente e respeito à natureza como conceito de EA, pontuados por E1, E2, E6, E7, E8. Isso remete à definição de EA da Lei 9.795/99, que dispõe sobre a educação, institui a Política Nacional de Educação Ambiental e dá outras providências:

"Art. 1‥ Os processos por meio dos quais o indivíduo e a coletividade constroem valores sociais, conhecimentos, habilidades, atitudes e competências voltadas 
para a conservação do meio ambiente, bem de uso comum do povo, essencial à sadia qualidade de vida e sua sustentabilidade" [4].

Foi pensando nesses princípios e conceitos de EA já apresentados que provavelmente o fundador do Instituto Terra, o fotógrafo Sebastião Salgado, tenha se inspirado, somando outras suas experiências profissionais em fotografar o planeta destruído, em resgatar a vida em uma fazenda devastada.

\subsection{A importância e contribuição da educação ambiental no contexto escolar}

Este pergunta, ao ser feita aos entrevistados, obteve uma variedade de opiniões (Tabela 2):

Tabela 2 - Importância e contribuição da educação ambiental no contexto escolar

\begin{tabular}{l|c}
\hline \multicolumn{1}{c|}{ Categorias } & Ocorrência \\
\hline Formação básica dos alunos, respeito à natureza/ sobrevivência do planeta & E1, E2, E4, E8 \\
\hline $\begin{array}{l}\text { Promoção do desenvolvimento local, mudança de visão, união e participação } \\
\text { da comunidade em relação ao meio ambiente }\end{array}$ & E7, E3 \\
\hline $\begin{array}{l}\text { Olhar mais crítico sobre o meio ambiente, informação sobre os problemas } \\
\text { ambientais, preservação e combate aos danos ambientais }\end{array}$ & E6 \\
\hline Promoção de inclusão social e estímulo à socialização & E5 \\
\hline
\end{tabular}

Fonte: dados das entrevistas.

Apesar dessa diversidade de opiniões, elas sempre convergem, não sendo divergentes nem contraditórias, ou seja: "promove o desenvolvimento, mudança de visão, união e participação da comunidade em relação ao meio ambiente" (E7, E3).

Todos esses elementos (mudança de visão, desenvolvimento local, união e participação) citados pelos entrevistados são características predominantes da EA emancipatória. Esses elementos se unem da seguinte forma [5]:

A educação ambiental emancipatória enfatiza a educação enquanto processo permanente, cotidiano e coletivo pelo qual agimos e refletimos, transformando a realidade de vida. Está focada nas pedagogias problematizadoras do concreto vivido, no reconhecimento das diferentes necessidades, interesses e modos de relações na natureza que definem os grupos sociais e o "lugar" ocupado por estes na sociedade, como meio para se buscar novas sínteses que indiquem caminhos democráticos, sustentáveis e justos para todos.

Refletindo sobre essa definição do autor, é possível concordar com o ponto de vista dos respondentes, ao se tratar da importância da EA e compreender como o Instituto Terra obteve sucesso com o reflorestamento da fazenda Bulcão. Pois é pela união e determinação de uma comunidade local que se torna possível superar os desafios presentes em um senso comum e modificar uma realidade. É o caso do Instituto Terra, a comunidade da cidade de Aimorés que, com o apoio das escolas e parcerias, conseguiu recuperar uma área totalmente degradada e devastada graças ao envolvimento e à participação de todos.

O sucesso do reflorestamento do Instituto Terra é aludido: 
Quando começamos a trabalhar no Instituto Terra, aqui era pura terra e cascalho. Ao iniciar as atividades de educação ambiental, surgiu a ideia de fazer o reflorestamento com os nossos alunos. Até que um dia esse propósito foi amadurecido e iniciaram-se as plantações e as coletas de mudas. Quando vimos nossas plantações ganhando vida, ficamos felizes e motivados, então decidimos homenagear cada muda e árvore plantada por um aluno, acrescentando o nome dele àquela muda, e hoje temos orgulho de ver essa floresta tão pura e tão bonita que engrandece os nossos olhos e a cidade de Aimorés (E3, 2012).

Diante dessa realidade, entende-se que a EA emancipatória pode contribuir de alguma forma para o desenvolvimento local, o qual já foi definido anteriormente. O Instituto Terra está diretamente ligado ao desenvolvimento local, pois contribui preponderantemente para a cidade de Aimorés em todos os sentidos, tais como: proporciona mais empregos e oportunidades de trabalho para os moradores da cidade; serve como ponto turístico e centro de estudos e pesquisa para as escolas e universidades; vitaliza a cidade, viabilizando melhor qualidade de vida. Esse elo entre a EA e o desenvolvimento local é reconhecido por um respondente, que confirma a melhoria da qualidade de vida e expõe sua experiência:

Em 2010 foi realizado o Projeto "Minha casa é 10" em parceria com o Programa Saúde Família (PSF). Esse projeto foi realizado em um vilarejo próximo de Aimorés, onde havia altos índices de verminoses causados pela falta de saneamento básico, higiene, etc. Esse projeto propôs à comunidade algumas tarefas como: retiradas de lixos, campanha tipo gincana, cuja premiação era dada para quem conseguisse manter a higienização da casa por mais tempo. Os moradores deixaram todos os coordenadores do projeto surpresos com a mudança radical de atitudes e o impacto da EA foi notória, pois a comunidade ficou mais unida e os cuidados básicos como a higienização passaram a ser um hábito constante, fato que sem dúvidas contribuiu para a redução de doenças verminose proporcionando, assim, melhor qualidade de vida aos moradores daquela comunidade. O patrocínio fez a diferença para se trabalhar a EA (E7, 2012).

\section{E acrescentou:}

Após a realização desse projeto, conseguimos perceber que a EA emancipatória consegue promover desenvolvimento local porque ela consegue mudar a visão dos moradores de um determinado local e consegue tornar a comunidade mais unida e participativa para realizar projetos.

Analisando o ponto de vista de três dos entrevistados (E7, E3 e E6) de que a EA é importante porque ela proporciona mudança de visão, união e participação da comunidade quanto ao meio ambiente, tornou-se relevante pontuar que o 5ㅇ artigo da Lei 9.795, de 27 de abril de 1999, pode ser relacionado à fala desses entrevistados. Isso se explica pelo fato de que esse artigo estabelece que a EA tem como objetivo incentivar a participação individual e coletiva, permanente e responsável, na preservação do equilíbrio do meio ambiente, entendendo-se a defesa da qualidade ambiental como um valor inseparável do exercício da cidadania.

Outra questão muito importante nos relatos é que a EA "promove inclusão social e estimula a socialização" (E5, 2012). Borges (2011) remete a algo relacionado ao ponto de vista desse entrevistado, afirmando que "as pessoas com deficiência devem ter assegurados seus 
direitos fundamentais como saúde, educação, trabalho e lazer. A ela devem ser concedidas iguais oportunidades de participação social, segundo suas capacidades" [6].

Este processo deve contemplar a educação ambiental, que pode ser através de exercícios físicos, recreação e contemplação da natureza que, sabidamente, proporciona a promoção da autoestima, socialização, contribuindo para a formação de um indivíduo com valores sociais, conhecimentos, habilidades, atitudes voltados para a conservação e uso sustentável do ambiente natural (E5, 2012).

Esse mesmo entrevistado narrou uma experiência vivida com EA versus inclusão social:

No ano passado, eu me deparei com uma aluna especial em minha sala de aula do 60 ano, a qual apresentava cegueira e autismo. Professor nenhum da escola conseguia trabalhar de forma evolutiva com essa aluna [...] eu ministrava minhas aulas [...] e ela ficava sentada quietinha na carteira. Até que um dia, eu precisei trabalhar a EA com os alunos, pois era a semana do meio ambiente e tínhamos então que expor uma feira de artesanato com produtos recicláveis. A partir daí, me deparei com uma cena muito emocionante, que marcou minha carreira docente... Ao levar os alunos para o pátio da escola onde ficaríamos ao ar livre para prepararmos as atividades de EA, essa aluna cega e autista confeccionou uma casa de folhas de jornal descartados (foram dadas aos alunos folhas de jornais não utilizados para realizar as atividades) enorme, que chamou a atenção de todos que estavam ao redor dela. Essa casa representava para ela o lar onde ela morava... e os seus colegas de classe durante essa atividade ficaram próximo dela o tempo todo observando e a ajudando pegar algo que ela manifestasse dificuldade. Desse dia em diante, descobrimos por acaso que os trabalhos manuais e as práticas pedagógicas de EA emancipatória estimula em todos os sentidos a socialização e a inclusão social dos alunos especiais $(E 5,2012)$.

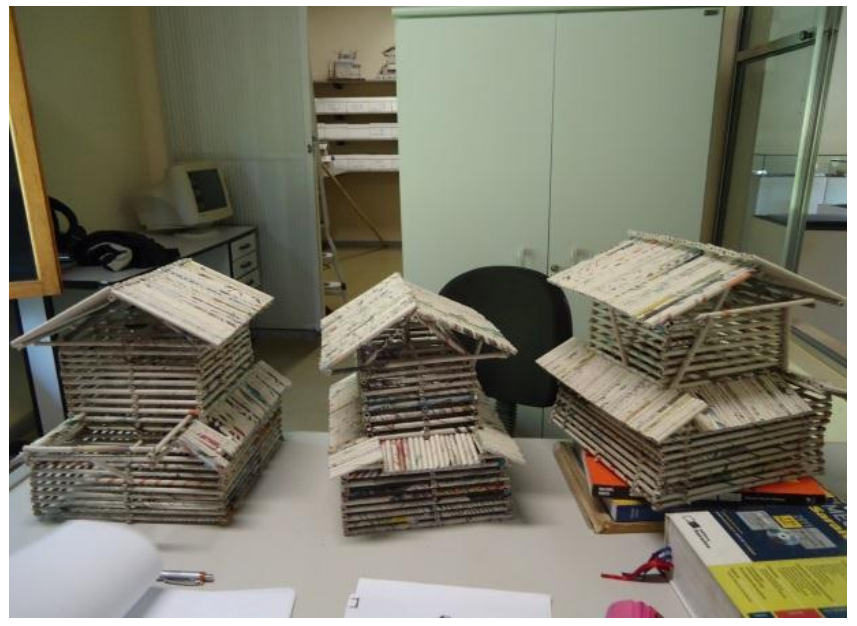

Figura 1 - Criações dos alunos do Instituto Terra em aula de Educação Ambiental. FONTE: da autora, a partir da fala de E5 (2012).

Analisando esse depoimento, é possível perceber que a EA emancipatória beneficia não só a natureza e seus recursos naturais, como também portadores de deficiência, pois:

O interesse em trabalhar as questões ecológicas, incluindo o público com necessidades especiais, nos remete a uma reflexão sobre sensibilização e o 
sentido mais íntimo de educação ambiental. A deficiência visual não é barreira para o contato com a natureza e há muitas iniciativas que estimulam a inclusão, mostrando que as belezas naturais, além de apreciadas com os olhos, podem ser também percebidas por outros sentidos [7].

Ainda de acordo com Maciel et al.

A inclusão de pessoas com deficiência em atividades em áreas naturais como exercícios físicos, recreação e contemplação da natureza proporciona a promoção da autoestima e socialização dessas pessoas. Esse fator concorre para a formação de um indivíduo com valores sociais, conhecimentos, habilidades, atitudes voltadas para a conservação e uso sustentável do meio ambiente e de uma visão holística sobre os espaços que compõem a cidade [7].

A EA contribui para a formação dos alunos a partir do momento em que se consegue sensibilizar o aluno com medidas básicas de educação como, por exemplo, "começando pela limpeza da sala de aula" (E4). O respondente justifica:

Em uma atividade de educação ambiental com os alunos do 5o ano do ensino fundamental, com o apoio da polícia ambiental da cidade de Aimorés, abordávamos o tema lixo. Durante essa atividade foi ensinada aos alunos a forma como deveríamos descartar variados tipos de lixo, em suas respectivas lixeiras. Os alunos no final desta atividade fizeram uma cesta de lixo de garrafas pet (descartadas pela cantina da escola) para ser levada todos os dias para a sala de aula, com a intenção de evitar jogar os lixos produzidos na sala de aula no chão, mantendo assim a limpeza da sala. Quando foi um belo dia, eu estava parado em um ponto de ônibus e encontrei-me com um aluno acompanhado pelo pai. O pai estava comendo um salgado e o aluno tomando um suco de caixinha, enquanto esperavam o ônibus passar. De repente, o aluno jogou seu suco em um lata de lixo próximo do ponto de ônibus e o pai jogou o papel do salgado no chão e nisso o ônibus passou para nos apanhar. O que mais me chamou a atenção nesta cena foi que o aluno ao invés de entrar no ônibus e seguir viagem, ele voltou e apanhou no chão o papel que o pai dele descartou, e nisso eu ouvi o pai falando: "por que você está fazendo isso, [fulano]? Pode deixar lá no chão, amanhã as formiguinhas irão varrer as ruas..." E o aluno firmemente respondeu: "Aprendi na escola essa semana, pai, que lixo é para ser jogado no lixo e não no chão, é para isso que existem as lixeiras próprias para serem descartados os papéis, como este do salgado que você acabou de comer!" O pai ficou tão envergonhado que recusou-se a entrar no ônibus. Ele voltou para o ponto do ônibus e aguardou o próximo. Fiquei chocado e ao mesmo tempo muito feliz com a atitude do meu aluno, pois pude ter certeza de que a educação ambiental, quando abordada na faixa etária certa, ela tem um retorno muito positivo, pois esse aluno de apenas 11 anos deu uma lição de moral para o próprio pai que supostamente apresentava a aparência de uns 35 anos [...] (E4, 2012).

A Figura 2 ilustra as aulas de EA, com parceria da polícia ambiental de Aimorés, referente ao tema "lixo". 


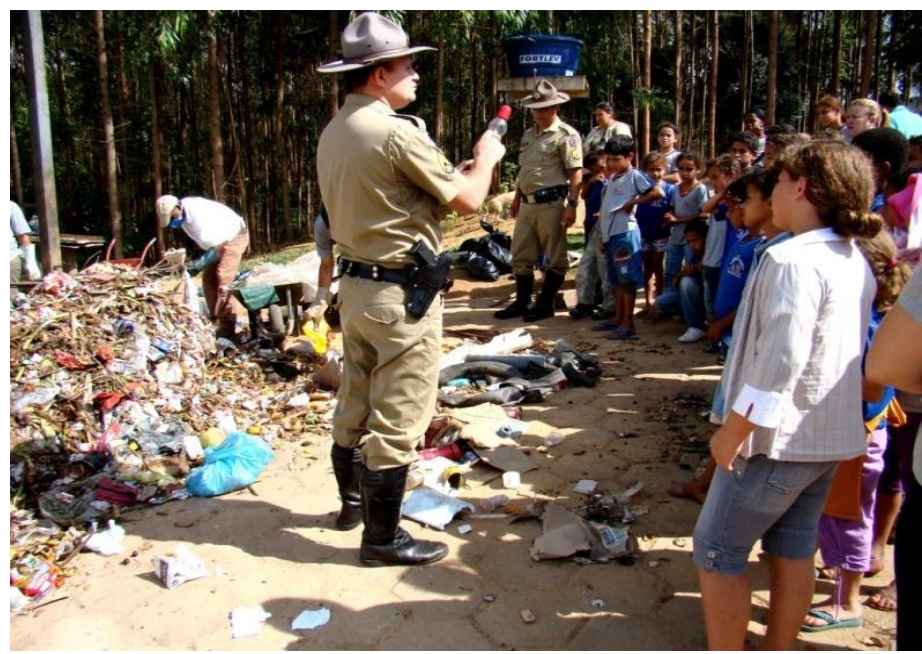

Figura 2 - Parceria com a polícia ambiental de Aimorés na aula sobre educação ambiental. FONTE: da autora, a partir da fala de E4 (2012).

A EA é um tema muito importante, porque o "meio ambiente" é um assunto que está sendo bastante contemplado no Exame Nacional de Ensino Médio (ENEM) e nos vestibulares e isso faz com que os alunos também percebam a necessidade de estarem inteirados sobre 0 assunto.

Nunes e Carvalho (2010, p. 29) argumentam:

O ENEM aplicado em 2009: constatamos a relevância do tratamento dos temas ambientais no exame, o destaque para o tema ambiental nas questões, não apenas na área das Ciências Naturais, mas também nas áreas que visam examinar as competências linguísticas, o juízo crítico dos jovens sobre a sociedade. Podemos imaginar que esta valorização dos temas e questões ambientais tem um potencial de ambientalização do ensino médio, na medida em que este deve preparar os alunos para esta avaliação [8].

A respeito do ensino médio, os autores acrescentam:

Seja por uma política de "resultados" seja pela associação da consciência ambiental como um tema condutor da ação cidadã para a juventude, parece-nos que as escolas de Ensino Médio tenderão a considerar as temáticas ambientais como relevantes no seu currículo formal e nas atividades formativas, projetos, entre outros espaços extracurriculares [8].

Tabela 3 - As práticas pedagógicas e recursos didáticos utilizados para trabalhar a EA

\begin{tabular}{l|c}
\hline \multicolumn{1}{c|}{ Categorias } & Ocorrência \\
\hline Aulas expositivas e trilhas ecológicas no parque botânico da cidade & E1, E4, \\
\hline Audiovisual, filmes, teatros, projetos feitos na escola, músicas, trabalhos & \\
artísticos, manuais, oficinas de reciclagem e programas oferecidos no & \\
Instituto Terra (oficinas, caminhada ecológica, etc.). & E7, E3, E2, E6, E5 \\
\hline
\end{tabular}

De acordo com os dados obtidos, apurou-se que grande parte dos professores utiliza variados recursos didáticos, prevalecendo, em sua maioria, o uso de filmes, teatros, projetos feitos na escola, etc. 
Antes de prosseguir na discussão sobre as práticas pedagógicas, é viável primeiramente abordar seu conceito, de acordo com alguns autores:

[...] é uma prática social específica, de caráter histórico e cultural que vai além da prática docente, relacionando as atividades didáticas dentro da sala de aula, abrangendo os diferentes aspectos do projeto pedagógico da escola e as relações desta com a comunidade e a sociedade [9].

São muitos os métodos para a realização da educação ambiental. Para determinado tema ambiental há diversas possibilidades metodológicas. $\mathrm{Na}$ escolha e na definição da metodologia de trabalho reside um dos aspectos que caracterizam a criatividade e a autonomia do professor diante dos desafios e das possibilidades que encontram cotidianamente [10].

Alguns respondentes, como E1 e E4, utilizam aulas expositivas como recursos pedagógicos. Reigota acredita que esse tipo de prática "não é muito recomendado na educação ambiental, mas elas podem ser muito importantes quando bem preparadas e quando deixam espaço para os questionamentos e a participação dos alunos" [10].

A Figura 3 mostra a aula expositiva ministrada por E4 aos alunos do ensino fundamental com o apoio da polícia ambiental, com o propósito de abordar o tema "animais silvestres".

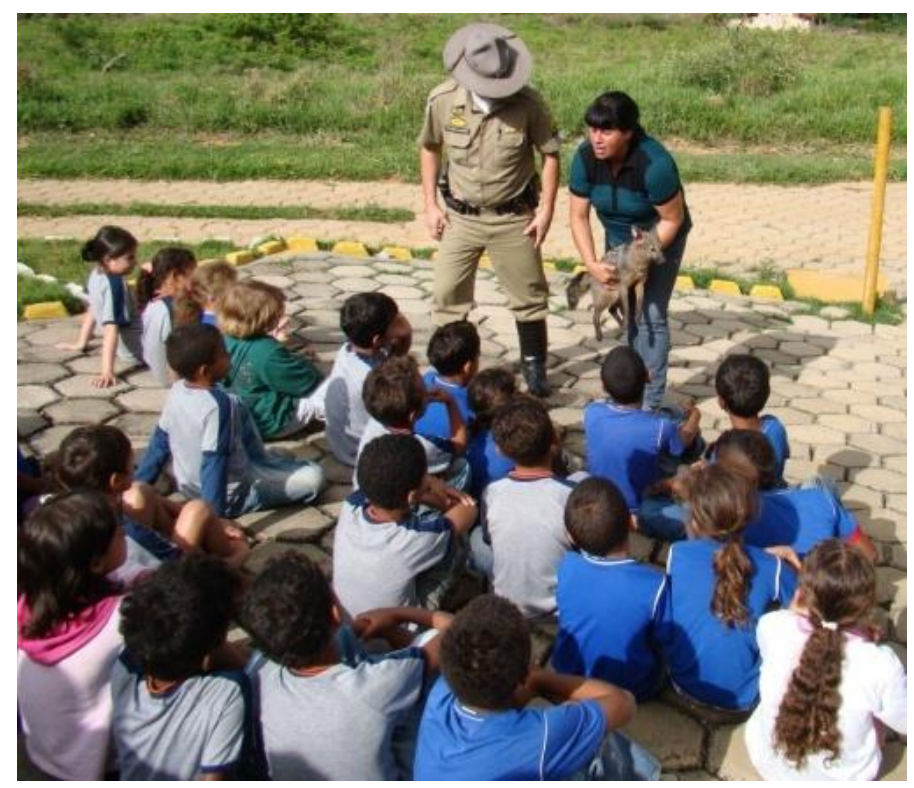

Figura 3 - Aula sobre política ambiental. FONTE: da autora, a partir da fala de E4 (2012).

Já as outras práticas pedagógicas citadas pelos demais professores, tais como audiovisual como filmes, músicas, teatros, caminhada ecológica, oficinas de reciclagem, projetos feitos na escola, etc., estão de acordo com o pensamento de Reigota, que defende esse tipo de metodologia:

Outras metodologias têm se mostrado muito adequadas para a realização da educação ambiental, entre elas podemos citar as histórias de vida e pedagogia de projeto. As histórias de vida podem ser apresentadas de forma oral, escrita ou visual (filmes e fotografias). Geralmente essa metodologia enfatiza as trajetórias e as relações de pessoas e grupos sociais com determinado tema em 
determinado momento histórico. É uma metodologia pedagógica que permite empregar a criatividade e expressar a compreensão de conceitos científicos e dos problemas ambientais em discussão [10].

Para ilustrar essa proposição de Reigota, apurou-se um fato que se enquadrou na metodologia de história de vida, trazendo resultado muito positivo para suas aulas de educação ambiental:

No final do bimestre passado, foi feito um trabalho de educação ambiental com os alunos do ensino fundamental de quatro escolas estaduais daqui de Aimorés. O tema que foi abordado era sobre a fauna, em especial "animais em extinção". Foi feito junto com a polícia ambiental uma palestra no auditório do Instituto Terra. Nesse dia o auditório estava lotado. Falávamos sobre o tamanduábandeira. Um dia antes de eu ministrar essa palestra, fui convocada pela polícia ambiental para fazer o reconhecimento deste animal em uma região próxima de Aimorés, que foi morto com apunhaladas [grifo nosso] na cabeça porque estava à procura de água, em plena luz do dia, sendo que este animal é de hábito noturno e extremamente inofensivo. Minha intenção com essa triste experiência vivida era de sensibilizar os alunos. Pois bem, foi falado tudo sobre o tamanduábandeira durante a palestra e no final eu contei a história desse tamanduá que estava em busca de água. Ao finalizar a palestra eu perguntei para os alunos: alguém sabe onde está esse tamanduá agora? Todos ficaram em silêncio e eu insisti na pergunta, até que um aluno levantou a mão e me perguntou: onde? Aí peguei o tamanduá morto e o coloquei em cima de mesa tampado com um lenço branco, falei: está aqui... Tirei logo em seguida o pano branco. A cena foi comovente, nunca imaginei ver crianças chorando... aí para finalizar foi dito: lembrem-se, não podemos deixar isso acontecer, temos que proteger os animais $(E 4,2012)^{1}$.

Ao analisar essa experiência relatada por E4, nota-se que seu objetivo foi atingido, pois conseguiu sensibilizar os alunos de forma mais comovente e trágica. A escolha desse recurso pedagógico foi positiva.

Esse tipo de método é defendido por alguns educadores, mas, de forma geral, por ser impactante, gera polêmica e é considerado uma técnica de "choque".

Entretanto, utilizam-se outras metodologias e estratégias de ensino como a pedagogia de projetos, sobre a qual Reigota $(2009$, p. 71$)$ enfatiza:

É um método que envolve toda a escola, incluindo os pais dos alunos no estudo de um tema específico. Ele permite que cada indivíduo desenvolva o tema proposto sob sua ótica, interesse e especificidade. Os pais participam contribuindo com a sua experiência e seu conhecimento sobre o tema. Os alunos se empenham em explorar particularidades que lhes interessam [10].

Exemplo de resultado muito positivo sobre a pedagogia de projetos que já foi mencionado foi do "Minha casa é 10", feito em parceria com o Programa Saúde da Família (PSF) de Aimorés, segundo E7.

\footnotetext{
${ }^{1}$ E4 é bióloga e trabalha com consultoria ambiental e remanejamento de fauna e flora em Aimorés.
} 
Ao analisar a fala desse professor, conforme já apresentado na íntegra anteriormente, é notório perceber que essa prática pedagógica adotada realmente funciona, pois é perceptível a limpeza das salas de aula e de toda a escola.

Fato interessante registrado em uma das escolas onde foram feitas as entrevistas inclui a rotina, a organização da escola e a educação dos alunos.

Durante o recreio os alunos compravam na cantina da escola diversos tipos de alimentos, com variadas embalagens (latas, sucos, papéis, caixinhas, embalagens de pipoca, salgadinhos, etc.). Ao terminarem o lanche, automaticamente descartavam o lixo nas devidas lixeiras (de recicláveis, de papéis e de orgânicos), evitando, assim, deixá-lo no chão.

Ao admirar a rotina desses alunos durante o recreio, uma funcionária responsável pela limpeza da escola declarou:

Não fazem ideia do quanto eles nos ajudam tendo essa pequena atitude, de jogar fora o seu próprio lixo na sua devida lixeira, pois facilita muito o nosso trabalho! Por exemplo, nós temos que varrer e limpar a escola inteira para recebê-los, e quando termina o expediente temos que limpar e varrer tudo de novo para receber os alunos de outros turnos, mas a educação junto com a educação ambiental faz com que a escola permaneça intacta, da forma como eles a receberam, ou seja, limpa e sem lixos no chão, nos poupando assim de fazer nosso serviço todo de novo (Encarregada da limpeza).

Apesar de parecer óbvia toda essa situação, ressalta-se aqui que há ainda muitas escolas na cidade de Belo Horizonte que não incorporaram esse tipo de consciência, a começar pelas lixeiras nas quais se podem separar os lixos. O mais comum de se ver são lixeiras do mesmo padrão espalhadas em todos os arredores da escola.

Essa consciência dos alunos em descartar seu próprio lixo é outra situação a ser considerada. É muito pouco comum encontrar uma escola onde a maioria dos alunos tem essa atitude e consciência. São poucas as que conseguem manter essa atitude ao se tratar do tema "lixo". Esclarece-se que esse dado não foi obtido nas entrevistas, tratando-se de uma constatação feita a partir da experiência da pesquisadora.

A prática pedagógica de oficinas de reciclagens foi levada à discussão:

Durante o início do ano retrasado, foi feito um desfile de roupa reciclável aberto a toda comunidade, a pedido dos alunos. Duas semanas antes do evento, os pais de muitos alunos compareceram à escola e ajudaram na limpeza, na organização, na decoração da escola. No dia do evento, a escola lotou e os pais, por incrível que pareça, foram os primeiros a chegar à escola [...] Os modelos e as roupas recicladas eram impecáveis, dava prazer em admirar! Os pais vibraram. Por incrivel que pareça, uma das mães que ajudou na confecção das roupas para o evento abriu uma lojinha na cidade, só de apetrechos reciclados, e hoje ela vende produtos para as lojas da cidade de Guarapari-ES. O que começou apenas com uma pequena ideia de descontração virou negócio na vida dessa mãe (E3, 2012).

\footnotetext{
${ }^{2}$ Essa funcionária não foi entrevistada, mas em conversa informal manifestou esse reconhecimento, o que evidencia o envolvimento de todos os funcionários da escola com essa mudança de comportamento dos alunos.
} 
A partir do comentário de E3, podem-se identificar alguns pontos positivos sobre a EA emancipatória no contexto escolar, como: a promoção da socialização; a participação e envolvimento de toda a comunidade, incluindo os pais de alunos; a gestão social; a colaboração de toda a comunidade para a organização do evento e mudança do cenário da escola, todos em busca de um propósito só: deixar a escola bem aparentada e decorada para receber os convidados e realizar o evento; e como desenvolvimento local, o negócio gerado pela mãe.

As trilhas ecológicas como prática pedagógica, defendido por Silva (2010, p. 12) [11], são abordadas:

A trilha ecológica é uma ferramenta importante para o ensino. Desta forma, o aprendizado é fixado com naturalidade, pois existe a interação com o meio ambiente e as pessoas são motivadas a perceberem a trilha. O local é um laboratório ao ar livre, onde é possível cultivar a vida e despertar nos visitantes o respeito à conservação da natureza. Na atualidade, o que se pode observar no ensino é a dificuldade da realização de atividades práticas em que o próprio aluno consiga desenvolver seu conhecimento (E1, 2012).

Na Figura 4 registra-se aula realizada por um professor (E1) no Instituto Terra, em que foi utilizada a trilha ecológica como recurso didático.

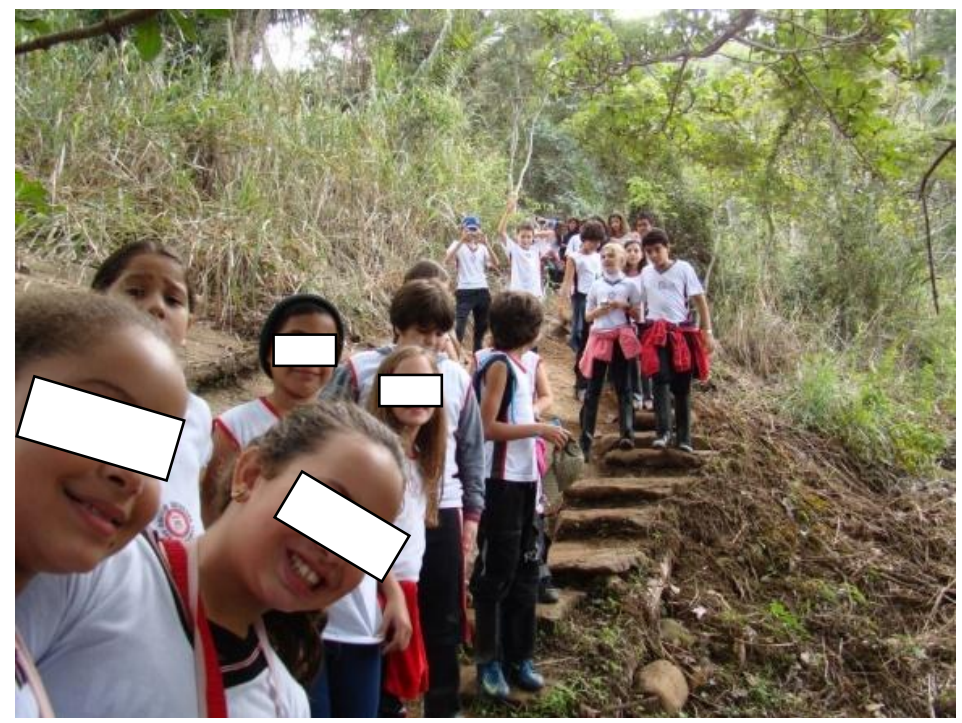

Figura 4 - Trilhas ecológicas no Instituto Terra. FONTE: da autora, a partir da fala de E1 (2012).

Ainda em se tratando de trilhas ecológicas:

Atualmente, as trilhas ecológicas estão previstas na Política Nacional de Educação Ambiental, instituída por meio da Lei Federal no 9.795, de 27 de abril de 1999 (BRASIL, 1999) e existe reconhecimento público da sua importância como ferramenta de educação, interpretação, comunicação e conscientização ambiental [12].

Os entrevistados que adotam as trilhas ecológicas como práticas pedagógicas esclareceram que elas são realizadas no Instituto Terra, fazendo-se um trabalho com os alunos dentro da própria mata e essas aulas contam com a presença dos monitores que prestam 
serviços ao Instituto Terra. Durante essas aulas, os alunos aprendem, com o auxílio dos professores e monitores, a identificar diversos tipos de plantas e animais, reconhecendo a sua importância naquele meio onde vivem. Esse tipo de aula facilita o trabalho do professor de Ciências e contribui de forma direta para o esclarecimento e entendimento do conteúdo de ecologia e ecossistemas presentes na disciplina Ciências e Biologia.

Outro recurso pedagógico muito interessante citado foi a confecção de hortas para exemplificar os trabalhos manuais e artísticos:

A melhor forma que eu encontrei para trabalhar a educação ambiental nas minhas aulas foi realizando no Instituto Terra o manuseio de hortas, onde os alunos aprendem a plantar com suas próprias mãos. Essas aulas possibilitam a abordagem de vários temas ligados a diversas disciplinas das séries correspondentes, como, por exemplo: solo, agrotóxicos, drenagem, adubos, água, mudas, fisiologia vegetal, etc. Esse tipo de trabalho apresenta uma riqueza enorme de informações, além disso, tenho muitos alunos que são filhos de agricultores, então de certa forma o que ele aprende aqui na escola e no Instituto Terra ele poderá multiplicar e aplicar seus conhecimentos no seu próprio cotidiano (E5, 2012).

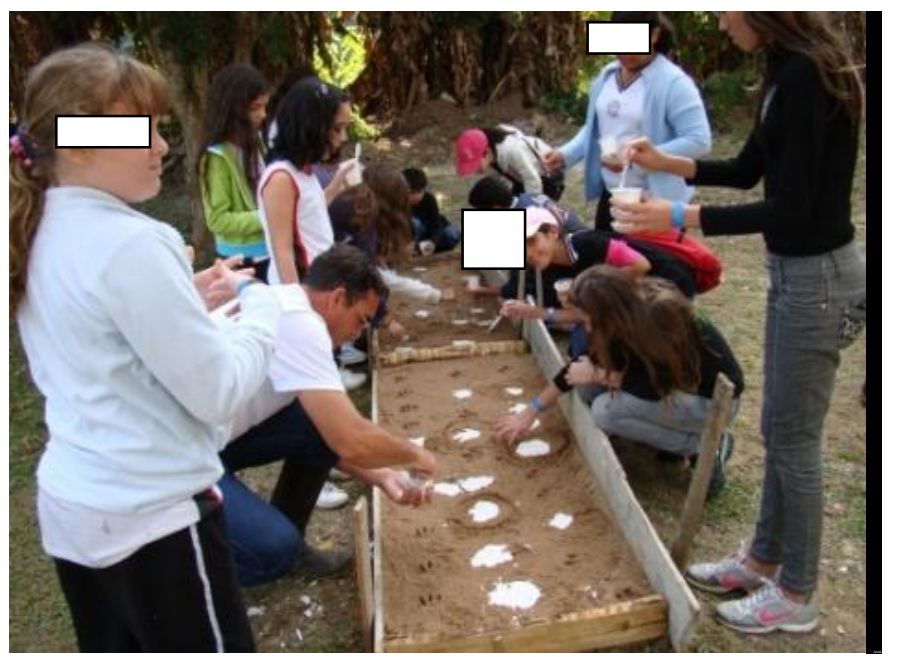

Figura 5 - Aula sobre técnica de fertilização do solo. FONTE: da autora, a partir da fala de E5 (2012).

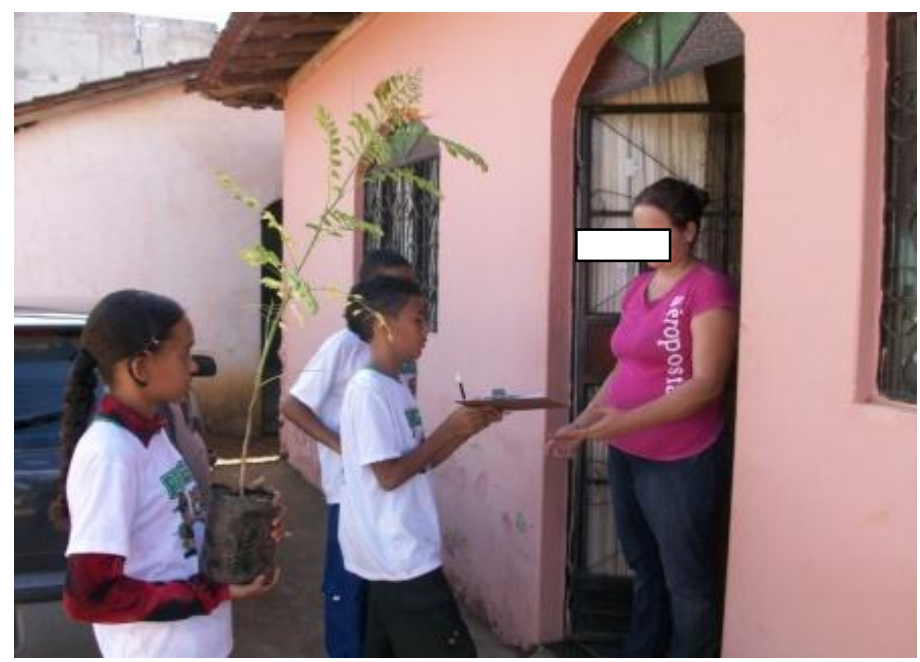

Figura 6 - Morador adota um verde plantado pelos alunos. Fonte: da autora, a partir da fala de E5 (2012). 
Cribb apoia esse recurso pedagógico escolhido por esse professor (E5), alegando que:

As atividades realizadas na horta escolar contribuem para os alunos compreenderem o perigo na utilização de agrotóxicos para a saúde humana e para o meio ambiente; proporciona uma compreensão da necessidade da preservação do meio ambiente escolar; desenvolve a capacidade do trabalho em equipe e da cooperação; proporciona um maior contato com a natureza, já que crianças dos centros urbanos estão cada vez mais afastadas do contato com a natureza. Proporciona também a modificação dos hábitos alimentares dos alunos, além da percepção da necessidade de reaproveitamento de materiais tais como: garrafas pet, embalagens, copos descartáveis, entre outros. Tais atividades auxiliam no desenvolvimento da consciência de que é necessário adotarmos um estilo de vida menos impactante sobre meio ambiente bem como a integração dos alunos com a problemática ambiental vivenciada a partir do universo da horta escolar [13].

A utilização de filmes, vídeos, teatros e músicas como alternativas de recursos didáticos sofre ressalva:

A música tem contribuído muito com o tema de educação ambiental, mas precisamos ficar atentos aos diferentes interesses que existem entre gerações. Indicar filmes é sempre um pouco mais complicado, pela dificuldade de acesso, mas hoje a produção brasileira e internacional, sobretudo curtas-metragens de cineastas jovens, é bem marcante [10].

Conforme observado, o Instituto Terra está sempre dando suporte e abrindo as portas para receber as escolas e facilitar o trabalho do professor quando o foco é EA.

No tocante aos recursos didáticos e às práticas pedagógicas utilizadas pelos professores de Aimorés, certifica-se que todos trabalham de acordo com os Parâmetros Curriculares Nacionais (PCNs) [14]. Pode-se constatar essa relação na Tabela 4.

Tabela 4 - Relação entre PCN e as práticas adotadas pelos professores entrevistados

\begin{tabular}{l|l}
\hline $\begin{array}{c}\text { Recurso didático/ } \\
\text { prática pedagógica }\end{array}$ & \multicolumn{1}{c}{ Relação direta com os PCNS } \\
\hline Trilha ecológica & $\begin{array}{l}\text { Fazer com que o aluno tenha percepção da existência e a } \\
\text { qualidade da interferência do homem na natureza, a } \\
\text { começar por sua própria realidade, tornando-se, assim, } \\
\text { mais consciente. } \\
\text { Estimular o aluno a ter argumentos para criticar a } \\
\text { qualidade dessa interferência, que reconheça valores que } \\
\text { induzirá à contribuição para a conservação e a manutenção } \\
\text { do ambiente mais imediato em que vive. } \\
\Omega\end{array}$ \\
& $\begin{array}{l}\text { Valorizar o uso adequado dos recursos disponíveis. } \\
\Omega\end{array}$ \\
& $\begin{array}{l}\text { Evitar o desperdício de recursos naturais que usa em sua } \\
\text { vida diária, tornando-se mais consciente. }\end{array}$ \\
\hline
\end{tabular}


Projetos

(Minha casa é 10)
- Induzir a participação do aluno nas atividades cotidianas de cuidado e respeito aos ambientes coletivos, mantendo a organização, e valorizar os aspectos estéticos nas dependências da escola, tornando-se assim mais participativo na comunidade local.

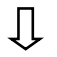

Valorizar o uso adequado dos recursos disponíveis.

I

Evitar o desperdício de recursos naturais que usa em sua vida diária, tornando-se mais consciente.

I

Estabelecer, para os alunos de todas as idades, uma relação entre a sensibilização ao meio ambiente, a aquisição de conhecimentos, a atitude para resolver os problemas e a clarificação de valores, procurando, principalmente, sensibilizar os mais jovens para os problemas ambientais existentes na sua própria comunidade;

Filmes, teatros,
músicas, trabalhos artísticos, manuais, oficinas de reciclagem e programas oferecidos no Instituto Terra (oficinas, caminhada ecológica, etc.)
Favorecer o aluno no contexto escolar, visto que a escola é um dos ambientes mais imediatos e constantes do aluno; o reconhecimento de fatores que produzam real bem-estar, estimulando, assim, a desenvoltura de um espírito crítico às induções ao consumismo e o senso de responsabilidade e solidariedade no uso dos bens comuns e recursos naturais, de modo a respeitar o ambiente e as pessoas de sua comunidade

\section{CONCLUSÕES}

A pesquisa teve como objetivo apresentar como é feito o trabalho de EA pelo Instituto Terra, junto às escolas localizadas em Aimorés, além de conhecer como se dá sua relação com professores e alunos.

A pesquisa de campo foi um forte norteador e contribuinte para a discussão e análises de dados para a realização deste estudo, pois a partir dela puderam-se apurar todos os dados dos professores, seguidos de seus conceitos, importância, facilitadores com que a educação ambiental é trabalhada e os tipos de recursos didáticos pedagógicos utilizados para se trabalhar a EA, tornando-se possível compreender como é feito o trabalho de cada docente.

O trabalho de campo também deu abertura para possíveis trocas de experiências, fato que muito contribuiu para o enriquecimento desta pesquisa e tornou-se um grande diferencial para se conhecer uma boa prática da EA, pois as experiências narradas pelos entrevistados serviram para ilustrar com clareza o funcionamento da EA nas escolas da cidade de Aimorés.

Este estudo possibilitou observar que, a partir da emancipação é possível compreender e praticar o conceito e os princípios da EA, a qual prioriza a mudança de comportamentos, possibilitando o uso e o manejo dos recursos naturais de forma mais consciente e responsável e tornando o indivíduo mais comprometido com os valores éticos e de solidariedade no exercício da cidadania. 
As práticas pedagógicas e os recursos metodológicos utilizados pelos professores constituíram um grande facilitador para a obtenção desse aprendizado e envolvimento do homem com a natureza.

Certificou-se também que o trabalho e o envolvimento do professor são fundamentais para trazer a EA para dentro das escolas, permitindo, assim, a aproximação dos alunos com a natureza.

Foi possível constatar, ainda, que o Instituto Terra é um importante centro de referência em EA e o ponto de apoio para toda a comunidade escolar da cidade de Aimorés (em especial para os alunos e professores). Constatou-se que, mesmo os professores apresentando, em algumas situaçãoes, dificuldades para explorar o tema de EA, tornou-se possível construir importantes aprendizados a partir de histórias? e relatos que modificaram a vida de muitas pessoas que tiveram a oportunidade de vivenciar e experimentar passar um dia fora da sala de aula para conhecer e praticar a EA.

O trabalho realizado junto à natureza, pelas escolas em Aimorés somado à participação e o envolvimento de todos nessa realidade parece ser o grande diferencial para o aprendizado dos alunos. Fora da sala de aula ele consegue observar e analisar melhor o mundo que está à sua volta, desvinculando-se, assim, da EA conservadora. O trabalho em campo possibilita ao aluno entrar em contato direto com a natureza, passar a enxergar e ter a oportunidade de construir seu próprio senso crítico, desprendendo-se, assim, dos livros didáticos inseridos todos os dias em uma sala de aula.

\section{REFERÊNCIAS}

1. REIGOTA, M. O que é educação ambiental. 3. ed. São Paulo: Brasiliense, 1994, p. 41.

2. SALGADO, I.D.W. Métodos, resultados e reflexões de um programa de educação ambiental do Instituto Terra. 1. ed. Aimorés: Câmara Brasileira do Livro, 2009, p. 10.

3. BARDIN, L. Análise de conteúdo. Lisboa, Portugal: Edições 70, 2011.

4. BRASIL. Ministério da Educação. Lei no 9.795 de 27/04/1999. Política Nacional de Educação Ambiental. Brasília, $1999 . \quad$ Disponível em: http://www.planalto.gov.br/ccivil_03/Leis/L9795.htm>. Acesso em: 20 de setembro de 2011.

5. LOUREIRO, C.F.B. Educação ambiental transformadora. In: LAYRARGUES, P.P. Identidades da educação ambiental brasileira. 1. ed. Brasília: MMA, 2004, p. 81.

6. BORGES, J.A.S. Educação ambiental e inclusão social. Revista Olhar de Professor, Ponta Grossa, v. 14, n. 2, p. 285-292, 2011.

7. MACIEL, J. et al. Metodologias de uma educação ambiental inclusiva 1. ed. Porto Alegre: EGP, 2010, p. 5.

8. NUNES, L.B.; CARVALHO, I.C. Ambientalização do ensino médio: impactos do Novo ENEM2009. 1. ed. Rio Grande do Sul, 2010, p. 30.

9. SILVA, J; RAMOS; M.M.S. Prática pedagógica numa perspectiva interdisciplinar. Brasília, 2006.

10. REIGOTA, M. O que é educação ambiental. 3. ed. São Paulo: Brasiliense, 2009, p. 64-81. 
11. SILVA, I.M.R. Práticas pedagógicas em educação ambiental: uma visão freiriana para um complemento na formação de normalistas. IN: CONGRESSO BRASILEIRO DE GESTÃO AMBIENTAL. ANAIS..., 2010, p. 12.

12. ROCHA, F.; BARBOSA, X.?; ABESSA, X.?. Trilha ecológica como instrumento de educação ambiental: estudo de caso e proposta de adequação no Parque Estadual Xixová. In: CONGRESSO BRASILEIRO DE GESTÃO AMBIENTAL, 2010, Bauru. Revista Brasileira de Ecoturismo. São Paulo, 3 v. p. 478-497, 2010.

13. CRIBB, S.L.S.P. Contribuição da educação ambiental e horta escolar na promoção de melhorias ao ensino, à saúde e ao meio ambiente. Revista REMPEC - Ensino, Saúde e Ambiente, São Paulo, v. 3, n. 1, p. 42-60, 2010, p. 8.

14. BRASIL. Secretaria de Educação Fundamental. Parâmetros Curriculares Nacionais: introdução aos parâmetros curriculares nacionais. Brasília: MEC/SEF, 1997. 126 p. 